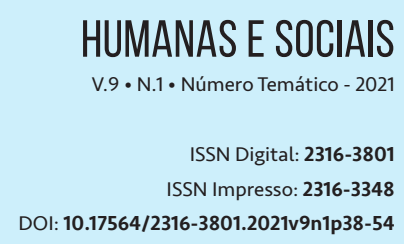

\section{O QUE OS OLHOS NÃO VEEM, OS VÍDEOS CONTAM}

OUT OF SIGHT, BUT NOT OUT OF REACH

OJOS QUE NO VEN, VIDEOS QUE NOS CUENTAN

Bianca Della Líbera ${ }^{1}$ Cláudia Jurberg ${ }^{2}$

NÚMERO TEMÁTICO:

"DEFICIÊNCIA, ACESSIBILIDADE E DIVULGAÇÃO CIENTíFICA”

\section{RESUMO}

São raros os materiais educativos sobre promoção da saúde acessíveis a indivíduos cegos e com baixa visão. Nesta pesquisa, buscamos identificar se vídeos de animação sobre ciência e saúde podem ser desenvolvidos sob uma perspectiva de acessibilidade, sendo compreensíveis ao mesmo tempo por surdos usuários de libras, ouvintes, pessoas com deficiência visual e videntes. Utilizou-se como metodologia a inserção do recurso de audiodescrição em três vídeos de animação produzidos sobre aspectos de fatores de risco relacionados ao câncer e a realização de grupos focais com sessão de filme e roda de conversa. Foram realizados três grupos focais com um total de 19 participantes com idade entre $14 \mathrm{e}$ 20 anos do $8^{\circ}$ e $9^{\circ}$ anos do ensino fundamental do Instituto Benjamin Constant, no Rio de Janeiro. A partir da experiência, constatou-se que jovens com deficiência visual tiveram a oportunidade de acesso a instrumento lúdico sobre saúde e ciência e que esse instrumento gerou debates além da expectativa de compreensão do conteúdo apresentado. Do ponto de vista educativo e da comunicação e saúde, concluímos que o desenvolvimento de materiais de qualidade para uso em contextos inclusivos, que contemplem diferentes necessidades, são viáveis e podem representar um importante movimento para uma inclusão verdadeira e ampla.

\section{PALAVRAS-CHAVE}

Inclusão. Deficiência Visual. Vídeo de Animação. Audiodescrição. Promoção da Saúde. 


\section{ABSTRACT}

Educational materials about health promotion that are accessible for people who are blind or visually impaired are rare. In this research, we seek to identify whether animation videos about science and health, produced according to accessibility guidelines, could be equally enjoyed by young people who use sign language and who are blind or visually impaired. Methodology included adding audio description to three animation videos about risk factors for cancer, and performing focus groups with film sessions and conversation circles. Three focus groups were carried, with a total of $19 \mathrm{~K}-12$ students, from 14 to 20 years of age, attending Instituto Benjamin Constant, Rio de Janeiro, Brazil. This experience showed that young people who are blind or visually impaired had the opportunity to access a playful instrument about health and science, which generated debate, exceeding expectations of understanding the content. From the educational and health communication point of view, we conclude that the development of quality materials to be used in inclusive contexts, addressing different needs, are feasible and can represent an important movement towards true and broad inclusion.

\section{KEYWORDS}

Inclusion, Visual Impairments. Animation Videos. Audio Description. Health Promotion.

\section{RESÚMEN}

Materiales educativos sobre promoción de la salud accesibles para personas ciegas o con discapacidad visual son raros. En esta investigación, buscamos identificar si los videos de animación sobre ciencia y salud se pueden desarrollar desde una perspectiva de accesibilidad, siendo comprensibles al mismo tiempo por usuarios sordos, oyentes, personas con discapacidad visual y videntes. Se utilizó como metodología la inserción del recurso de audiodescripción en tres videos de animación producidos sobre aspectos de factores de riesgo relacionados con el cáncer y la realización de grupos focales con sesión de cine y rueda de conversación. Se realizaron tres grupos focales con un total de 19 participantes con edades entre los 14 y los 20 años, de la escuela secundaria de Instituto Benjamin Constant, en Río de Janeiro, Brasil. A partir de la experiencia, se descubrió que los jóvenes con discapacidad visual tuvieron la oportunidad de acceder a un instrumento lúdico sobre salud y ciencia, y que este instrumento generó debates más allá de la expectativa de comprensión del contenido presentado. Desde el punto de vista educativo y de comunicación y salud, concluimos que el desarrollo de materiales de calidad para uso en contextos inclusivos, que aborden diferentes necesidades, es factible y puede representar un movimiento importante hacia una inclusión verdadera y amplia.

\section{PALABRAS-CLAVE}

Inclusión, Ceguera y Discapacidad Visual, Videos De Animación, Audiodescripción, Promoción De La Salud. 


\section{INTRODUÇ̧̃̃o}

No Brasil, estima-se que $1,1 \%$ da população apresenta deficiência auditiva e 3,6\% apresenta deficiência visual (DV), que engloba a cegueira e a baixa visão, sendo esta deficiência a mais prevalente na população (IBGE, 2015). Pessoas com deficiência estão entre os grupos mais vulneráveis, tanto pelas especificidades da deficiência quanto por sua posição entre os mais pobres, o que traz consequências diretas para qualidade de vida (MUNGUBA et al., 2015).

As discussões no campo da saúde, partindo da década de 1960, foram diversificadas na busca de superar o conceito de saúde como oposição à doença e de pensar orientações políticas e técnicas sobre o processo saúde-doença-cuidado (BUSS, 2009). Assim, trabalhamos com a perspectiva da promoção da saúde, que busca envolver a comunidade em ações que visam "promover a qualidade de vida, reduzir vulnerabilidades e riscos à saúde relacionados aos seus determinantes e condicionantes - modos de viver, condições de trabalho, habitação, ambiente, educação, lazer, cultura, acesso a bens e serviços essenciais" (MUNGUBA et al., 2015, p. 463).

0 acesso à informação é fundamental para a promoção da saúde, pois permite que as pessoas alcancem o conhecimento técnico e a consciência política necessários para que possam tomar decisões informadas nos níveis individual e comunitário (BUSS, 2009). Contudo, o acesso à informação não é equânime na população e pessoas com deficiência encontram obstáculos nesse processo. No início deste século, o acesso a materiais acessíveis para jovens com DV era um grande desafio (KOVÁCS, 2000), mas com o desenvolvimento de diferentes recursos tecnológicos, principalmente os digitais, as barreiras comunicacionais diminuíram expressivamente.

Podemos argumentar que, considerando esse potencial de uso, plataformas digitais e redes sociais se constituem como espaço importante para ações de promoção da saúde, na medida em que esses recursos tecnológicos podem moldar comportamentos (NUNES, 2019). Segundo a Teoria da Aprendizagem Social de Albert Bandura (2001), o aprendizado é um fenômeno que pode ser apontado como bidirecional, ou seja: "aprendemos com o meio e o meio se modifica graças às nossas ações".

A partir desta máxima, podemos refletir sobre a capacidade dos indivíduos causarem efeitos uns nos outros. Nos últimos anos, essa teoria tem sido aplicada em estudos de comunicação de massa e aponta o poder que as redes sociais teriam sobre os indivíduos. Essa proposição se aplica de forma bem exemplar, nos dias de hoje, no ambiente virtual e, principalmente, na propagação de informações divulgados pelas redes sociais.

Bandura (1988, 2001) e Middleton, Hall e Raeside (2019) afirmam que ao observar dicas, comportamentos e suas consequências, os indivíduos usam essas informações para refletir seu próprio comportamento no dia a dia. Em sua revisão de literatura, esses últimos autores ainda ressaltam outros estudos sobre a aplicação da teoria na educação em saúde, no incentivo a estilos de vida saudáveis e ainda em relação, inclusive, a certas condições médicas (KREBS et al., 2017). Neste sentido, a mudança no "consumo" de informação traz, sem sombra de dúvidas, impacto social devido ao fato de os indivíduos aprenderem regras sociais de comportamento por meio de outras instâncias, como as principais redes como Facebook, Instagram, YouTube e Twitter. 
Esse impacto pode ser maior na adolescência (10 a 19 anos), período de transição entre a infância e a vida adulta e é uma etapa em que o desenvolvimento físico, mental, emocional, sexual e social se soma ao esforço empreendido para atender às expectativas estabelecidas pela sociedade em que se está inserido (EISENTEIN, 2005). Assim, neste relato de experiência, trazemos uma ação de promoção da saúde direcionada a adolescentes do ensino fundamental com deficiência visual (DV).

Esta é uma população que necessita de atenção. Ela vivencia as questões próprias dessa etapa de vida, no contexto das limitações experimentadas a partir da deficiência, mas estudos demonstram que os jovens com DV possuem um estilo de vida similar aos videntes e que as restrições cotidianas, muitas vezes, são impostas por quem os apoia e não por inabilidade individual (DELLA LÍBERA; JURBERG, 2017; SILVA, 2018). Portanto, é preciso que as condições necessárias a uma boa qualidade de vida para os jovens estejam acessíveis também àqueles com deficiência (MARINHO; VIEIRA, 2015).

Iniciativas prévias com vídeos de animação e videojogos sobre temas de saúde direcionadas ao público jovem surdo já demonstraram que estas podem, ao refletir sobre a acessibilidade no desenvolvimento de produtos, avaliá-los de forma a dar proeminência ao público-alvo a que se destina, resultar em uma comunicação verdadeira (JURBERG et al., 2013; VERJOVSKY, 2014).

Diante das experiências de nosso grupo, buscamos avaliar a viabilidade e a eficiência no desenvolvimento de materiais de divulgação científica universais com um sentido de inclusão por diferentes públicos-alvo, incluindo, surdos, ouvintes, cegos ou indivíduos com baixa visão e videntes. Neste relato, com o intuito de oferecer conhecimento de qualidade a um público ampliado e assim democratizar o acesso a informação em saúde, implementamos o recurso da audiodescrição (AD) em vídeos de animação sobre fatores de risco relacionados ao câncer, incluindo três temáticas: o vírus do Papiloma Humano (HPV), o álcool e o sedentarismo. 0 objetivo do estudo foi verificar em que medida a AD inserida em vídeos já produzidos favorece a compreensão do conteúdo por pessoas com deficiência visual.

A opção pelo vídeo em formato de animação foi em virtude de ser um instrumento que gera empatia e que pode desencadear respostas emotivas (ROOIJ, 2019), expandindo a possibilidade de compreensão de aspectos científicos e da saúde (SEIBER, 2014; MCGILLION, 2017), de forma mais fluida e gerando a possibilidade de maior divulgação.

A AD é uma técnica de tradução visual que usa linguagem sucinta, vívida e imaginativa para tornar acessível, principalmente àqueles que não enxergam, o conteúdo visual de diferentes meios (SNYDER, 2014). Caracteriza-se como um recurso de tecnologia assistiva que a partir de critérios específicos busca empoderar o público com DV, fornecendo informações visuais relevantes para que formem uma imagem mental do evento (SEEMANN, 2019).

Contudo, é importante ressaltar que não somente pessoas com DV se beneficiam da AD, já que esse recurso também pode ampliar o entendimento de idosos e de pessoas com baixo letramento, deficiência intelectual, autismo, dislexia e déficit de atenção, entre outras (MOTTA, 2016). Assim, o recurso da $A D$ permite a fruição desse material audiovisual por públicos com diferentes necessidades.

Segundo revisão integrativa realizada por Galindo Neto e colaboradores (2019), os vídeos educativos são a tecnologia mais utilizada na educação em saúde de pessoas surdas, sendo esse recurso bem compreendido por esse grupo. Em contrapartida, há escassez de literatura sobre o assunto no caso de 
pessoas com DV em diferentes bases de dados quando buscamos pela palavra-chave audiodescrição (audio description), recurso essencial para que a pessoa com DV tenha acesso a imagens.

Na plataforma da US National Library of Medicine, do National Institutes of Health/PubMed (https://www.ncbi.nlm.nih.gov/pubmed/), dos nove artigos encontrados, apenas um citava vídeo educativo, ao descrever o processo de adaptação de material digital sobre saúde e segurança do trabalho contendo vídeos (ALMEIDA et al., 2020). No portal de periódicos do grupo SAGE Journal (www.sagejournal.com), encontramos sete estudos sobre audiodescrição, e destacamos o que descreve a experiência de um vídeo audiodescrito utilizado por 12 professores cegos em uma pesquisa em Uganda (WORMN/ES; SELL/EG, 2013). No Scientific Eletronic Library Online/Scielo (www.scielo.br), nenhum dos 14 artigos identificados tratava de vídeos educativos ou de temáticas da saúde.

Os resultados contribuem para reflexões acerca da falta de materiais acessíveis sobre variadas temáticas e em diferentes suportes para esse público no mundo. Recursos audiovisuais são muito utilizados como recurso pedagógico, mas o senso comum, verificado em nossa experiência e em relatos encontrados na literatura (SNYDER, 2014), é de que pessoas com DV não precisariam ter acesso a esses recursos, uma vez que dependem majoritariamente do sentido da visão. No entanto, estudos apontam que quando a $A D$ está disponível o nível de fruição desses produtos é semelhante entre pessoas com e sem DV (LOPEZ; KEARNEY; HOFSTÄDTER; 2018; HÄTTICH; SCHWEIZER, 2020). Assim, acreditamos que a escassa produção de material audiovisual direcionado a pessoas com DV estaria relacionada ao desconhecimento de recursos de acessibilidade e do papel desses recursos no acesso a informação pela pessoa com DV.

Ressaltamos, também, a raridade de estudos que analisam os processos de elaboração e testagem desses materiais. Quando se busca por literatura acerca de educação, comunicação e saúde, praticamente não há menção a ações direcionados a jovens com deficiência. Algumas propostas encontradas foram o uso de redes sociais na construção colaborativa de conhecimento (DELLA LíBERA; JURBERG, 2020a) e o caso de materiais adaptados sobre diabetes para cegos (WILLIAMS, 2009).

A essa preocupante produção baixa de conteúdo sobre saúde com informações relevantes e de qualidade, soma-se a inexistência de estudos que analisem a compreensão dessas produções por parte das pessoas surdas ou com deficiência visual. No caso da temática saúde, esse cenário de baixa produção de materiais acessíveis e pouca avaliação de eficácia e eficiência apontam para uma lacuna que poderia ser o despertar do interesse dessa camada da sociedade pela importância de hábitos de vida saudáveis ou ainda sobre questões relativas à prevenção, fatores de risco ou do diagnóstico precoce de certas doenças.

\section{MÉTODO}

Este estudo é componente do projeto de pesquisa $O$ uso de tecnologia na deficiência visual, surdocegueira e deficiência múltipla, aprovado pelo Comitê de Ética em Pesquisa da Faculdade de Medicina de Valença (CEP-FMV), sob o número 1.969.383.

Os vídeos utilizados estão disponíveis no YouTube, no canal do Programa de Oncobiologia (https://www.youtube.com/user/Oncobiologia). A seguir, apresentamos um resumo do conteúdo de cada um deles. 
1. “Amor em tempos de HPV" apresenta a relação entre o vírus do Papiloma Humano e o câncer. 0 enredo se desenrola por meio de uma história de amor entre os personagens criados em massa de modelar, caracterizando um pênis, o Pintoso; e uma vagina, a Gina, a trama discute o uso ou não de preservativos e os riscos associados de desenvolver cânceres de faringe, laringe, pulmão e nos genitais (VERJOVSKY, 2014);

2. “Do álcool e seus demônios” aborda a percepção pública sobre o álcool, sua associação ao câncer e a influência da propaganda no comportamento. Neste vídeo, o personagem Oscar sofre influência da mídia para beber, beber e beber e, no desfecho da animação, de forma lúdica, o espectador pode escolher entre dois finais (JURBERG et al., 2015);

3. "Relatos de um sedentário" trata da correlação entre sedentarismo e risco, aumentando de uma neoplasia maligna em uma animação cujo personagem principal é inspirado em Mário, criado pela Nintendo e que se tornou um ícone dos jogos eletrônicos. De forma lúdica, discute o sedentarismo na adolescência e os vícios em games.

A AD dos vídeos foi realizada por uma empresa especializada, sendo os roteiros validados antes da conclusão do produto final por uma voluntária cega adulta, com experiência em consultoria de AD e por professoras da escola especializada. Entre os profissionais envolvidos, estavam uma especialista em audiodescrição, uma bióloga (responsável por esta pesquisa) e uma pedagoga. Concluído o processo, cada um dos vídeos foi apresentado em um grupo focal distinto.

Os grupos focais foram realizados com estudantes com deficiência visual, cegos e com baixa visão, do Instituto Benjamin Constant, instituição federal especializada em deficiência visual localizada no Rio de Janeiro, RJ. Antes da participação, os estudantes tiveram acesso ao Termo de Consentimento Livre e Esclarecido sob diversos formatos (DELLA LÍBERA; JURBERG, 2020b).

Os participantes tinham entre 14 e 20 anos e estavam matriculados no $8^{\circ}$ e $9^{\circ}$ ano do ensino fundamental, etapa em que já haviam tido contato inicial com os conteúdos abordados nos vídeos, por meio das atividades da área de Ciências da Natureza, em especial aquelas relacionadas à competência 6 da Base Nacional Curricular Comum (BNCC) : "Utilizar diferentes linguagens e tecnologias digitais de informação e comunicação para se comunicar, acessar e disseminar informações, produzir conhecimentos e resolver problemas das Ciências da Natureza de forma crítica, significativa, reflexiva e ética" (BRASIL, 2017, p. 324).

Para as atividades, todos os alunos de $8^{\circ}$ e $9^{\circ}$ ano, cerca de 50, foram convidados a participar da atividade e os grupos foram realizados com 19 alunos que compareceram nos dias e horários divulgados. Quatro alunos participaram de mais de um grupo. A composição de cada grupo está resumida no Quadro 1.

Os encontros em formato de grupo focal foram idealizados sob a perspectiva de Colucci (2007), que destaca a relevância do uso do lúdico e seu impacto na realização das atividades, também de Gaskel (2002), para quem estes propiciam um debate aberto, acessível e de interesse em comum. Tiveram duração aproximada de uma hora e foram gravados em áudio para posterior transcrição e análise dos dados. Nas citações diretas de falas dos estudantes, os participantes cegos estão identificados pela letra $\mathrm{C}$ e aqueles com baixa visão pelas letras BV. 
Quadro 1 - Composição dos grupos focais. Total de 23 participantes nos três grupos, sendo compostos por 19 alunos

\begin{tabular}{|c|c|c|}
\hline Vídeo & $\begin{array}{c}\text { Número de } \\
\text { estudantes cegos }\end{array}$ & $\begin{array}{c}\text { Número de estudantes } \\
\text { com baixa visão }\end{array}$ \\
\hline O amor em tempos de HPV & 5 & 4 \\
\hline Do álcool e seus demônios & 5 & 3 \\
\hline Relatos de um sedentário & 3 & 3 \\
\hline
\end{tabular}

Fonte: Dados da pesquisa.

Na totalidade dos grupos focais, todos os participantes assistiram primeiro ao filme sem AD. Embora a $A D$ seja imediatamente relacionada a pessoas cegas, aquelas com baixa visão também podem se beneficiar, pois seu resíduo visual nem sempre permite a compreensão de imagens, por isso optamos pelos grupos mistos. Esta estratégia visou observar, inicialmente, a capacidade dos participantes com baixa visão de entenderem as mensagens de saúde dos vídeos e avaliar, posteriormente, se a AD tinha sido capaz de fornecer elementos que auxiliassem na elucidação de aspectos não compreendidos na primeira exposição.

Após a exibição sem AD, conversamos isoladamente com os estudantes com baixa visão para saber o que eles haviam compreendido. Por fim, todos assistiram ao vídeo mais uma vez, agora com AD, realizamos uma roda de conversa com o grupo, cuja função era ouvir as impressões de cada um e promover discussões acerca do assunto abordado na animação. À mediadora da roda, professora da instituição, coube o papel de apresentar as questões norteadoras da discussão e organizar a fala dos participantes. Num grupo em que há pessoas com deficiência visual, onde as pistas não verbais nem sempre são percebidas, esta organização é importante para que todos tenham a oportunidade de se expressar adequadamente.

Para verificar se a AD permitiu que os participantes tivessem acesso ao conteúdo apresentado nos vídeos, a discussão feita na roda de conversa foi norteada por questões elaboradas previamente, separadas em dois blocos: sobre o conteúdo e sobre o recurso da AD. As perguntas estão listadas no Quadro 2.

Quadro 2 - Perguntas norteadoras da roda de conversa

\begin{tabular}{|c|c|}
\hline Questões relacionadas ao conteúdo & Questões relacionadas à AD \\
\hline $\begin{array}{c}\text { O que você entendeu do vídeo? } \\
\text { Quais foram os pontos que considerou mais } \\
\text { importantes? }\end{array}$ & $\begin{array}{c}\text { A AD ajudou ou atrapalhou a compreensão do } \\
\text { vídeo? } \\
\text { O que achou mais interessante? }\end{array}$ \\
$\begin{array}{c}\text { Houve alguma coisa que você só entendeu após a } \\
\text { versão com AD? O quê? (direcionada aos partici- } \\
\text { pantes com baixa visão) } \\
\text { qual seria? }\end{array}$ & \begin{tabular}{c} 
Encontrou algum problema na AD? Qual? \\
\hline
\end{tabular} \\
\hline
\end{tabular}

Fonte: Dados da pesquisa. 
Após o encerramento da roda de conversa, os participantes responderam individualmente em arquivos digitais a um formulário de reação ao vídeo. Os estudantes acessaram e responderam o questionário em computadores com recursos de tecnologia assistiva de sua escolha (Sistema Dosvox ou leitores de tela). A opção pelo recurso tecnológico permitiu que o questionário fosse respondido de forma mais rápida do que usando material impresso (Braille ou tinta ampliada) e ofereceu maior privacidade para as respostas do que no debate aberto. As questões eram: 1) Você daria um like ou deslike para o vídeo? Por quê? 2) Escreva um comentário para o vídeo; 3) Você compartilharia esse vídeo em outra rede social? Qual? Por quê?

\section{RESULTADOS E DISCUSSÃO}

Durante o processo de validação dos roteiros de AD, foi possível discutir questões relacionadas a seu conteúdo e forma, assim como a aplicação das diretrizes de AD em contexto educacional. A multiplicidade de profissionais envolvidos na construção da audiodescrição nesse contexto é importante, considerando as especificidades de cada um dos campos de conhecimento envolvidos: a tradução audiovisual, a pedagogia e a saúde. A troca de saberes entre os campos promoveu a confecção de um roteiro que, mais do que se encaixar no modelo ideal de $A D$, buscou atender as necessidades do público-alvo (FRANCO, 2013).

Nesse sentido, um ponto de discussão foi a quantidade e qualidade da informação presente no roteiro de $A D$, considerando as diretrizes de $A D$ e o objetivo do vídeo. As diretrizes indicam que 0 roteirista descreva estritamente aquilo que vê, contando com o conhecimento prévio da pessoa para que a informação seja plenamente compreendia (SNYDER, 2014).

No entanto, tais diretrizes não contemplam a multiplicidade de contextos educacionais, culturais e sociais no qual os sujeitos estão inseridos, nem suas necessidades específicas, relacionadas ou não a uma deficiência. Dessa forma, e, considerando que um material que se pretende educativo muitas vezes requer informação específica para compreensão do que está sendo mostrado, nos pareceu importante incluir informações que auxiliassem na formação da imagem mental, também dos conceitos que estavam sendo apresentados.

Um problema apontado pela consultora cega foi a quantidade de informação condensada em um pequeno espaço de tempo. Uma vez que os vídeos originais foram pensados para o público vidente e surdo, optou-se pela animação sem diálogos. Num segundo momento, considerando limitações financeiras que impediam a produção de novos vídeos, buscamos verificar se a inclusão de $A D$ como recurso de acessibilidade permitiria que ampliássemos o público-alvo desses vídeos.

No caso dos cegos e de pessoas com baixa visão, a adaptação mostrou, como desvantagem, que a $A D$ ficou longa e a locução, rápida, porém compreensível. Tais características também fizeram com que, em alguns momentos, a AD estivesse fora de sincronia com as ações mostradas no vídeo. Apesar dos ajustes feitos, que contribuíram para uma AD mais fluida, entendemos que o desenvolvimento do roteiro já deve prever a $A D$, de forma que seja possível coordenar o tempo das ações que se desenrolam no vídeo com o tempo necessário à $A D$. Ao se pensar na criação de novos instrumentos, essas características poderão ser contornadas. 
A seguir, detalhamos a realização de cada um dos grupos focais.

\section{Vídeo 1 - O amor em tempos de HPV}

Este vídeo traz de forma lúdica a importância de se debater o uso de preservativo nas relações sexuais. Os estudantes assistiram ao vídeo sem AD. Durante a sessão, percebemos que um dos estudantes com baixa visão explicava o filme para uma colega cega, fazendo uma AD informal do vídeo. Essa é uma prática observada nas exibições de vídeo feitas na escola, ainda que esses vídeos possuam AD, assim como é relatada por pessoas que assistem a vídeos em suas casas ou nos cinemas (DAVID; HAUTEQUESTT; KASTRUP, 2012), onde o recurso de AD não costuma estar disponível, apesar da legislação em vigor apontar para sua necessidade (BRASIL, 2015).

Ao término da sessão, conversamos separadamente com os estudantes com baixa visão para verificar sua compreensão sobre o vídeo. Quando solicitados que recontassem a história, obtivemos a seguinte narrativa:

Um homem e uma mulher se encontraram, aí, tipo, rolou uma cantada, aí um gostou do outro, eles foram para a cama e não levaram camisinha. Aí, nasceu o bebê... não, o bebê foi se desenvolvendo, começou a se desenvolver, aí a mulher chegou num lugar e explicou o que aconteceu, tipo, explicou os riscos que podem causar aquilo, e depois refizeram de novo o vídeo, só que agora eu fiquei meio confuso se a camisinha entrou no bolo ou não entrou (BV1). Até aquele ponto que eles foram pra cama pela primeira vez dava pra entender, mas depois dali é que o negócio ficou confuso (BV2).

Os estudantes fizeram a conexão dos elementos que reconheceram no vídeo - um casal e a camisinha - com uma situação que faz parte de seu conhecimento prévio - sexo sem camisinha pode resultar em gravidez. No entanto, a parte do vídeo que mostrava a infecção pelo HPV e a ida da personagem ao médico, que esclarece o processo de infecção e os perigos do vírus para a saúde, não foi bem compreendida. Este resultado corrobora a importância da AD para grupos além dos cegos (FRANCO, 2013; MOTTA, 2016).

No segundo momento, todos os estudantes assistiram ao filme com AD, e seguiu-se uma roda de conversa sobre o tema da animação. Logo após a projeção do vídeo, o participante com baixa visão que havia feito a $A D$ durante a exibição sem $A D$ reconheceu que "errei algumas partes, pensei que era uma coisa e depois vi que era outra. Na parte que mostrava ele se infectando, eu pensei que era o bebê se desenvolvendo" (BV1). O participante BV2 afirmou que o vídeo com AD foi mais interessante, pois permitiu que entendesse a parte do filme que havia ficado confusa quando vista na versão sem AD.

Quando convidamos os participantes cegos a recontar a história, a narrativa foi mais colaborativa do que aquela feita anteriormente pelos estudantes com baixa visão, mas de uma riqueza sobre detalhes do roteiro que nos impressionou.

Sobre a importância do vídeo, uma das participantes afirmou que "o vídeo mostra que a gente tem que pensar antes... pensar duas vezes antes de fazer alguma coisa, porque depois que a gente faz, aí já era, adeus" (C1). 
Os participantes também trouxeram para a discussão a vacinação contra o HPV. Três estudantes afirmaram ter tomado a vacina, quatro afirmaram não ter tomado e dois não souberam responder. Percebemos nessas narrativas, como Bandura (1988, 2001), Middleton e colaboradores (2019) sugerem, que ao observar dicas, comportamentos e suas consequências, os indivíduos usam essas informações para refletir sobre seu próprio comportamento no dia a dia.

Após assistir à animação com AD, os participantes foram capazes de relacionar HPV a vírus do papiloma humano, respondendo que é transmitido pelo contato sexual e que pode causar câncer (sem citar tipos específicos) e verrugas.

Além de apresentar informações sobre transmissão, consequências e prevenção do HPV, o vídeo também se mostrou importante na discussão de tópicos relacionados à educação para a sexualidade, que não estavam previstos, mas emergiram espontaneamente nas falas dos participantes.

Uma primeira questão foi a importância da camisinha na prevenção tanto de uma gravidez indesejada quanto de infecções sexualmente transmissíveis. Uma das participantes comentou que toma remédios (pílula anticoncepcional), mas que também manda o parceiro usar camisinha, pois "previne de doenças, aids, HPV, e tudo mais" (C2).

A seguir, outro participante iniciou uma discussão sobre planejamento familiar e paternidade responsável, afirmando que "é pra você pensar duas vezes antes de fazer qualquer coisa, porque uma criança não é brinquedo, é uma coisa pra toda a vida, você vai ter que bancar a responsabilidade” (BV2). Novamente, os conceitos de Bandura $(1988,2001)$ emergem ao refletirmos sobre a capacidade dos indivíduos causarem efeitos uns nos outros em rodas de conversa sobre saúde e prevenção de doenças.

Antes de encerrar o grupo focal, pedimos que todos respondessem individualmente algumas perguntas de avaliação do vídeo. Os nove respondentes afirmaram que dariam like, citando que a informação era importante para si e para os outros na prevenção de doenças. Nos comentários, escreveram que o vídeo é importante, legal, interessante, que seria compartilhado com amigos, reforçando sua importância como instrumento de divulgação e o fato de que, por meio do compartilhamento, a informação chegaria a mais pessoas. As respostas obtidas mostram a importância das redes sociais na influência que os sujeitos exercem uns sobre os outros (BANDURA, 1988, 2001).

\section{Vídeo 2 - Do álcool e seus demônios}

Neste vídeo, busca-se debater a influência da sociedade e dos meios de comunicação na decisão pelo consumo do álcool, que leva principalmente jovens a beber não por iniciativa espontânea e autônoma, mas por uma imposição externa, para ser aceito como um igual em seu grupo, ser reconhecido como descolado e antenado. Neste vídeo, após ser apresentado a uma situação-problema relacionada ao consumo excessivo de álcool, o espectador é convidado a escolher um final para a situação apresentada.

Sobre a temática, a participante C3 comentou que assistiu a várias palestras sobre o assunto, mas que não gosta desse tipo de atividade pois sempre são “histórias tristes”. Este relato nos ajuda a refletir sobre o foco excessivo dado a aspectos biomédicos em ações de promoção da saúde, também indica que precisamos avançar no uso de estratégias que valorizem o conhecimento popular e a participação social (BUSS, 2009). 
Durante a exibição do vídeo sem $A D$, percebemos a tentativa da participante $C 3$ de criar uma narrativa para a história a partir da trilha sonora do vídeo. A escolha do final é apresentada também em áudio e, por isso, a participante $\mathrm{C} 3$ fez um resumo das duas alternativas apresentadas para outro participante que não havia compreendido bem as opções.

Os alunos com baixa visão tiveram uma ideia geral da temática, mas não evidenciaram a discussão central pretendida no roteiro. Obtivemos desses participantes a seguinte narrativa sobre o entendimento do vídeo:

O cara não parava de beber, o vídeo todo foi falando de bebida (BV4). O cara vivia uma vidinha meio ruim (BV5), se alcoolizando (BV3), uma rotina praticamente igual todos os dias, bebia pra caramba e não parava (BV5). Aí veio uma pessoa falando com ele, que ele vivia bebendo (BV3).

Após a exibição com AD, os participantes avaliaram o vídeo como educativo, porque apresenta "os riscos de beber muito" (C5) e "se beber pouco também não tem segurança de que não vai ficar com câncer" (C6). Quando perguntados sobre o que entenderam sobre o vídeo, obtivemos a seguinte narrativa:

Era um cara que vivia uma vida normal e assim, de repente, do nada, acabou entrando no vício alcoólico só por causa de um comercial. É meio surreal mas, ao mesmo tempo, nem tanto (C5). Porque as possibilidades de você ser influenciado por um comercial que passa na mídia é bem grande. É bem mais fácil você ser influenciado por um amigo, por um colega ou então seu namorado do que ser influenciado por um comercial, mas... (C5)

Os demais participantes concordaram com essa fala e afirmaram que não são influenciados por propagandas, embora admitissem que outras pessoas, de "cabeça fraca” (BV3, C3), poderiam sofrer essa influência. Para esses participantes, uma pessoa de cabeça fraca é a que "vai pela cabeça dos outros, que tudo que a pessoa fala acredita e quer experimentar o tempo todo" (C3). Essas falas reforçam a teoria de Davison (1983) que discute a impressão que os indivíduos têm do poder de influência da mídia nos outros, mas raramente em si mesmos. E neste sentido, a animação foi idealizada para gerar exatamente esse tipo de debate e mostrar seus aspectos contraditórios.

Ao longo da discussão, pudemos perceber que esses participantes entendem a adoção de maus hábitos como uma característica puramente individual, que não sofre influência do meio, pois "a pessoa só para de beber, ou para de fumar, para de fazer coisas ruins, que vai (sic) prejudicar ela, quando ela quer” (C7).

Os participantes também relataram que conheciam a relação entre o álcool e certas doenças, como a cirrose e o câncer, e que esse conhecimento é advindo de filmes e séries de TV. Apesar das afirmações anteriores, de que não são influenciados pela mídia, esse relato nos indica que, mesmo que os sujeitos não estejam cientes do processo, a mídia exerce alguma influência sobre eles (DAVISON, 1983)

No questionário de avaliação após o vídeo, os oito participantes responderam que dariam um like para o vídeo, ressaltando que o conteúdo é importante e pode ajudar a conscientizar as pessoas acerca dos malefícios do álcool. Também avaliaram a AD como boa, e expressaram o desejo de ter acesso a "mais produtos com o mesmo conteúdo e com AD". 
Vídeo 3 - Relatos de um sedentário

Neste vídeo, busca-se apresentar como os fatores alimentação e sedentarismo se relacionam com o combate ao câncer.

Uma estudante cega que participou do grupo do vídeo 2 esteve presente também neste grupo e comentou:

Era um cara jogando, ele foi teletransportado para dentro do jogo e ficou jogando no lugar do boneco. Ele teve que comer, porque tava ficando sem energia, e pegou poder porque tava ficando fraco. Ele estava comendo mais... ele não comeu comida... a pizza. Ele só comeu biscoito e fruta. 0 vídeo foi um incentivo para a alimentação correta (BV6).

Após a exibição com AD, os participantes, principalmente os cegos, apontaram o excesso de informação contido na AD como um fator que atrapalhou o entendimento de partes do vídeo. 0 participante C8 comparou o processo de acompanhamento da AD com o ato de "ler um livro em velocidade rápida”: é possível acompanhar, mas perdem-se alguns detalhes.

Apesar desse excesso de informação condensado em um curto espaço de tempo, os participantes resumiram a ideia central do vídeo como "a luta contra o sedentarismo e contra o câncer" (C8). Também relacionaram maus hábitos alimentares e o sedentarismo como fatores de risco para o câncer e definiram natural killers como células que combatem células tumorais.

A partir do vídeo, também houve uma breve discussão sobre o sistema de defesa do organismo, levando os participantes a resgatar conhecimentos adquiridos nas aulas de ciências em séries anteriores.

Apenas quatro dos seis participantes responderam o questionário de avaliação após o vídeo. Todos disseram que dariam like e avaliaram o vídeo como dinâmico, informativo, "bom para todo mundo aprender". Afirmaram que o compartilhariam em outras redes sociais, principalmente Facebook e WhatsApp. Sobre a AD, afirmaram que foi "dinâmica e bem-feita, apesar de rápida", também houve um elogio à iniciativa de se apresentar vídeos educativos com AD.

\section{CONSIDERAÇÕES FINAIS}

O processo de adaptação de vídeos educativos para pessoas com DV nos mostrou que é possível desenvolver materiais de qualidade que contemplem diferentes necessidades específicas. A opção por um vídeo de animação sem diálogos tem apelo a vários públicos, pois a presença de informações em língua portuguesa e em Libras contempla a população surda, a inclusão da AD amplia o acesso a pessoas com deficiência visual ou intelectual, além daquelas que por alguma outra condição tenham dificuldade na compreensão da linguagem fílmica.

Embora os vídeos tenham sido concebidos como peças de divulgação, durante a realização dos grupos focais percebemos que há potencial para sua utilização em ações de educação formal. Eles foram capazes de fomentar discussões espontâneas de assuntos variados e essa potencialidade pode ser mais bem explorada a partir de planejamento para a utilização pedagógica do material, com mediação de um professor. 
Reforçamos a necessidade de se incluir o fator diversidade em todas as etapas do desenvolvimento de qualquer material educativo, considerando a baixa produção de material direcionado ao público com deficiência e os achados deste estudo. Problemas encontrados na adaptação do material audiovisual para a pessoa com DV, como a grande quantidade de informação a ser incluída num curto espaço de tempo e a falta de clareza em alguns pontos da AD, podem ser minimizados quando a acessibilidade é pensada desde a concepção do projeto.

Além disso, é importante enfatizar que pessoas com deficiência precisam ser mais do que público-alvo dos projetos e avaliadores do produto final. É preciso que essas pessoas sejam incluídas como atores protagonistas dos processos, participando desde o início da concepção e desenvolvimento dos materiais. Somente quando participarem de todas as etapas, poderemos dizer que estamos contribuindo verdadeiramente para a inclusão das pessoas com deficiência nas ações de promoção de sua saúde. Quando os olhos não veem, os vídeos podem contar histórias, divertir e até ensinar.

\section{REFERÊNCIAS}

ALMEIDA, Ana Margarida Pisco et al. Development of an online digital resource accessible for students with visual impairment or blindness: Challenges and strategies. Work, v. 65, n. 2, p. 333-342, 2020. Disponível em: https://content.iospress.com/articles/work/wor203085. Acesso em: 15 maio 2020.

BANDURA, Albert. Organizational application of Social Cognitive Theory. Australian Journal of Management, v.13, n. 2, p. 275-302, 1988.

BANDURA, Albert. Social Cognitive Theory: an agentic perspective. Annual Reviews of Psychology, v. 52. n. 1, p. 1-26, 2001. Disponível em: https://doi.org/10.1146/annurev. psych.52.1.1. Acesso em: 18 mar. 2020.

BRASIL. Lei no 13.146, de 6 de julho de 2015. Institui a Lei brasileira de inclusão da pessoa com deficiência (Estatuto da pessoa com deficiência). Brasília: Câmara dos Deputados, 2015. Disponível em: http://www.planalto.gov.br/ccivil_03/_ato2015-2018/2015/lei/l13146.htm. Acesso em: 15 abr. 2016.

BRASIL. Ministério da Educação. Base Nacional Comum Curricular. Brasília, 2017.

BUSS, Paulo Marchiori. Uma introdução ao conceito de promoção da saúde. In:

CZERESNIA, Dina; FREITAS, Carlos Machado de (org.). Promoção da Saúde: conceitos, reflexões, tendências [livro eletrônico]. 2. ed. Rio de Janeiro: Editora Fiocruz, 2009.

COLUCCI, Erminia. Focus groups can be fun: The use of activity-oriented questions in focus group discussions. Qualitative Health Research, v. 17, p. 1422-1433, 2007. 
DAVID, Jéssica; HAUTEQUESTT, Felipe; KASTRUP, Virginia. Audiodescrição de filmes: experiência, objetividade e acessibilidade cultural. Fractal: Revista de Psicologia, v. 24, n. 1, p. 125-142, 2012. DOI: https://doi.org/10.1590/S1984-02922012000100009.

DAVISON, W Phillips. The Third-Person Effect in communication. Public Opinion Quarterly, v. 7, n. 1, p. 1-15. 1983. DOI: https://doi.org/10.1086/268763.

DELLA LÍBERA, Bianca; JURBERG, Claudia. Teenagers with visual impairment and new media: A world without barriers. British Journal of Visual Impairment, v. 35, n. 3, 2017. DOI: https://doi. org/10.1177/0264619617711732.

DELLA LÍBERA, Bianca; JURBERG, Claudia. Communities of practice on WhatsApp: A tool for promoting citizenship among students with visual impairments. British Journal of Visual Impairment, v. 38, n. 1, p. 58-78, 2020. DOI: https://doi.org/10.1177/0264619619874836.

DELLA LÍBERA, Bianca; JURBERG, Claudia. Compreender para atuar: o Termo de Consentimento Livre e Esclarecido para participantes de pesquisa com deficiência visual. Benjamin Constant, v. 1, n. 61, 2020. Disponível em: http://revista.ibc.gov.br/index.php/BC/article/view/702. Acesso em: 18 abr. 2020.

EISENSTEIN, Evelyn. Adolescência: definições, conceitos e critérios. Adolescência e Saúde, v. 2, n. 2, p. 6-7, 2005. Disponível em: http://www.adolescenciaesaude.com/detalhe_artigo.asp?id=167. Acesso em: 6 dez. 2018.

FRANCO, Eliana P. C. Revelando a deficiência e a eficiência, o ver e o não ver por meio da pesquisa sobre audiodescrição. Benjamin Constant, ed. esp. 3, 2013. Disponível em: http://ibc.gov.br/ revistas/271-edicao-especial-03-outubro-de-2013. Acesso em: 15 mar. 2019.

GALINDO NETO, Nelson Miguel et al. Tecnologias para educação em saúde de surdos: revisão integrativa. Texto \& Contexto Enfermagem, v. 28, n. e20180221, p. 1-14, 2019. DOI: http://dx.doi. org/10.1590/1980-265X-TCE-2018-0221.

GASKELL, George. Entrevistas individuais e grupais. In: GASKELL, George; BAUER, Marti W. (org.). Pesquisa qualitativa com texto, imagem e som: um manual prático. Petrópolis: Vozes, 2002. p. 64-89.

IBGE- Instituto Brasileiro de Geografia e Estatística. Pesquisa Nacional de Saúde 2013: Ciclos de vida: Brasil e grandes regiões. Rio de Janeiro: IBGE, 2015. Disponível em: http://biblioteca.ibge.gov. br/visualizacao/livros/liv94522.pdf. Acesso em: 8 nov. 2016. 
JURBERG, Claudia; VERJOVSKY, Marina; MACHADO, Gabriel; RUMJANEK, Vivian M. Overcoming barriers: the development of an animated film on HPV for deaf and hearing students. Scholarly Journal of Scientific Research and Essay, v. 2, n. 2, p. 27-33, 2013.

JURBERG, Claudia; MACHADO, Gabriel de Oliveira Cardoso; REGO, Tainá Maia; SOUTO, Helena Magarinos. Álcool e câncer: análise da percepção de uma amostra da população por meio da ferramenta SurveyMonkey ${ }^{\circledR}$. Revista Eletrônica Comunicação, Informação \& Inovação em Saúde, v. 9, n. 3, p.1-13, 2015. Disponível em: http://www.reciis.icict.fiocruz.br/index.php/reciis/article/ view/982. Acesso em 10 mar. 2020

KOVÁCS, Krisztina. Hungary: Changing attitudes in the education of children and youth with a visual impairment. British Journal of Visual Impairment, v. 18, n. 2, p. 61-67, 2000. DOI: https://doi. org/10.1177/026461960001800206.

KREBS, Paul; SHTAYNBERGER Jonathan; MCCABE, Mary; IOCOLANO, Michelle; WILLIAMS, Katie; SHUK, Elyse; OSTROFF, Jamie S. An eHealth intervention to increase physical activity and healthy eating in older adult cancer survivors: Summative evaluation results. JMIR Cancer, v. 3, n. 1, 2017. DOI: http://doi.org/10.2196/cancer.6435.

MACGILLION, Chris. Animation as a Science Communication tool in Timor-Lest. Science Communication, v. 39, n. 2, 2017. DOI: https://doi.org/10.1177\%2F1075547017696164.

MARINHO, Christielle Lidianne Alencar; VIEIRA, Sandra Conceição Maria. Qualidade de vida em adolescentes com necessidades especiais em um município de Pernambuco. Revista Brasileira em promoção da Saúde, v. 28, n. 1, p. 50-57, 2015. Disponível em: https://periodicos.unifor.br/RBPS/ article/view/2891/pdf. Acesso em: 20 mar. 2020.

MIDDLETON, Lindsay; HALL, Hazel; RAESIDE, Robert. Applications and applicability of Social Cognitive Theory in information science research. Journal of Librarianship and Information Science, v. 51, n. 4, p. 927-937, 2019. DOI: https://doi.org/10.1177/0961000618769985.

MOTTA, Lívia Maria Villela de Mello. Audiodescrição na escola: Abrindo caminhos para a leitura de mundo. Campinas: Pontes Editores, 2016.

NUNES, Alexandre Morais. Comunicação através das redes sociais digitais: Contributos para a promoção da saúde. Alceu - Revista de Comunicação, Cultura e Política, v. 20, n. 38, p. 129-141, 2019. Disponível em: http://periodicos.puc-rio.br/index.php/revistaalceu/article/view/924. Acesso em: 8 maio 2020. 
ROOIJ, Malou. Carefully constructed yet curiously real: how major American Animation Studios generate empathy trhough a shared style of character design. Animation, v. 14, n. 3, 2019. DOI: https://doi.org/10.1177\%2F1746847719875071.

SEEMANN, Paulo Augusto Almeida. A produção de roteiros de áudio-descrição de vídeos feita por iniciantes: dificuldades comuns e sugestões para evitá-las. Revista Educação Especial, v. 32, p. 1-22, 2019. DOI: http://dx.doi.org/10.5902/1984686X35720.

SEIBER, Tim. Playable vírus: HIV molecular aesthetics in science and popular culture. Animation, v. 9, n. 2, 2014. DOI: https://doi.org/10.1177\%2F1746847714526661.

SILVA, Bianca Della Líbera da. Um mundo sem barreiras: Estudantes com deficiência visual discutindo saúde nas mídias sociais. 2018. Tese (Doutorado em Ensino em Biociências e Saúde) Instituto Oswaldo Cruz, Fiocruz, Rio de Janeiro, 2018.

SNYDER, Joel. The visual made verbal: A comprehensive training manual and guide to the history and applications of audio description. Arlington: American Council of the Blind, 2014.

VERJOVSKY, Marina. Divulgação do câncer para jovens em 3 atos: HPV, tabagismo e exposição solar. 2014. Tese (Doutorado em Gestão e Difusão em Biociências) - Instituto de Bioquímica Médica Leopoldo de Meis, Universidade Federal do Rio de Janeiro, Rio de Janeiro, 2014.

WILLIAMS, Ann S. Making diabetes education accessible for people with visual impairment. The Diabetes Educator, v. 35, n. 4, p. 612-621, 1 jul. 2009. Disponível em: http://tde.sagepub.com/cgi/ content/abstract/35/4/612. Acesso em: 12 mar. 2020.

WORMNÆES, Siri; SELL/EG, Nina. Audio-described educational materials: Ugandan teachers' experiences. British Journal of Visual Impairment, v. 31, n. 2, p. 164-171, 2013. DOI: https://doi. org/10.1177/0264619613485029. 
1 Professora do Ensino Básico, Técnico e Tecnológico e da Pós-Graduação em Ensino na Temática da Deficiência Visual - Instituto Benjamin Constant. Doutora em Ciências - Fiocruz/RJ. E-mail: biancadellalibera@ibc.gov.br

2 Professora dos cursos de Pós-Graduação de Ensino de Biociências em Saúde do Instituto Oswaldo Cruz/Fiocruz e de Educação, Gestão e Difusão em Biociências do Instituto de Bioquímica Médica Leopoldo de Meis/UFRJ. Doutora em Educação, Gestão e Difusão em Biociências - UFRJ. E-mail: cjurberg@yahoo.com.br

\section{(). (1) (-)}

Este artigo é licenciado na modalidade acesso abertosob a Atribuição-Compartilhalgual CC BY-SA

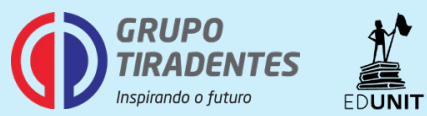

